\title{
The Effect of Voltage on the Arc Stud Welding of Microwave Sintered Fe+Al Powder Mixture
}

\author{
Şükrï Talaş ${ }^{a *}$, Mustafa Doğan ${ }^{b}$, Mehmet Çakmakkaya ${ }^{a}$, Adem Kurt ${ }^{c}$ \\ ${ }^{a}$ Faculty of Technology, A. Kocatepe University, Afyonkarahisar, Turkey \\ ${ }^{b}$ Graduate School of Natural Sciences, A. Kocatepe University, Afyonkarahisar, Turkey \\ 'The Faculty of Technology, Gazi University, Ankara, Turkey
}

Received: July 14, 2013; Revised: April 20, 2014

\begin{abstract}
The joining of powder metallurgy products is of importance because of high demand in many industrial applications. In this study, the effect of welding voltage on the joint quality has been investigated using discharge arc stud welding, a low heat input welding method, without gas protection to join steel stubs to microwave sintered compacts containing a powder mixture of 26 atomic $\% \mathrm{Al}$ and $\mathrm{Fe}$ (balance). It has been shown that welds with steel stubs are prone to side cracking in the weld zone and they also suffer from the oxidation of metal powders adjacent to weld zone. The forms of oxides are continuous and laminar type in welds with steel stubs and the composition of weld zone changes with increasing arc voltage.
\end{abstract}

Keywords: powder metallurgy, stud welding, microwave sintering

\section{Introduction}

Powder metallurgy (P/M) is one of the most-in-demand methods of producing the parts which are difficult to produce by conventional fabrication methods in manufacturing industry. The specific demands from working parts such as high wear and/or high corrosion resistance and complexity in shape can all be met with this method without extensive post production processing. Studies regarding the joining of $\mathrm{P} / \mathrm{M}$ parts are very limited in the literature. In addition, the joining of powder compacts is complicated since they expose great difficulty due to their porous structure and low thermal conductivity compared with bulk metals and alloys ${ }^{1}$. The joining of sintered powders are mostly carried out by low heat input joining methods such as diffusion bonding, sinter joining or brazing to itself or other metals, alloys and ceramics due to metallurgical and dimensional effects of high heat input on sintered powder compacts ${ }^{2-8}$. Diffusion bonding produces joints that are relatively stable to high operating temperatures and therefore, the service temperature of the joint is elevated without excessive change in dimensions and the possibility of remelting of compacts. High heat input joining methods such as MMA (Manual Metal Arc welding), MIG (Metal Inert Gas welding) or TIG (Tungsten Inert Gas welding), need shorter joining time, also, bring about the risk of a) remelting of metal powders due to high temperature and low thermal conductivity, b) porosity and swelling due to evaporation and excessive oxide formation of some elements with low partial vapour pressures c) formation of brittle phases that are undesirable for the joint and d) post weld cracking due to differences in thermal expansion coefficients of powders and/or their compacts $^{9,10}$. Low heat input techniques such as HSPW (High Speed Pulse Welding) is employed to successfully join the $\mathrm{P} / \mathrm{M}$ products since the effect of heat source is less, so is its post weld stress. It is also easier to deal with the size of the joint of high input joining unlike diffusion bonding, requiring an inert gas or a low pressure gas tight chamber and high contact load for bonding, which limit the dimension of the parts to be bonded. Brazing of PM parts is in use for some applications. It is also carried out in comparatively shorter duration of heating cycle and reaction time and its fast filling action is due to fast occurring liquid-solid contact diffusion ${ }^{11}$ but, the use of low melting compound to join mating surfaces is a considerable disadvantage for high temperature applications.

Similar to high speed pulse welding, joining of P/M products by using CDFW (Capacitive Discharge Flash Welding) was carried out by Aarup et al. and Halldin et al. ${ }^{12,13}$ on $\mathrm{Al}$ alloys and stainless steels, respectively. Flash welding on Al alloys was not successful in terms of ductility; however, the trials with stainless steel sintered P/M products yielded better results. This is partly because of characteristics of $\mathrm{Al}$ and its alloys due to an active layer of impenetrable oxide preventing the formation of successful sintering whereas Fe based alloys are more successful to join $^{14}$. The joint stability appears to be reasonable with stud welding but the joints have experienced a post-weld cracking problem lying parallel along to the joint line.

In this study, the microwave sintered $\mathrm{Fe}+\mathrm{Al}$ powder mixtures are attempted to join by using arc stud welding with low carbon steel stud at different arc voltages. The XRD (X-Ray diffraction) technique and SEM (Scanning Electron Microscope) were used to characterize the sintered powder mixtures and the weld zone. 


\section{Experimental Procedure}

The base metal specimens used in this study were prepared from high purity $\mathrm{Al}$ and Fe powders which were purchased from Alfa Aesar. Typical purity of the powders is higher than \%99.5. Following the preparation of mixture of $\mathrm{Fe}+26$ at.\% (atomic \%) Al, the compaction of $\mathrm{Al}$ and $\mathrm{Fe}$ powders were carried out in single axis die using $400 \mathrm{MPa}$ compaction pressure. Following the compaction, the powder compacts were heat treated in Microwave oven at $550{ }^{\circ} \mathrm{C}$ for $1 \mathrm{hr}$. The thickness of the sintered powder disks were $4.4 \mathrm{~mm}$. Fe stubs ( $4 \mathrm{~mm}$ in diameter) and the weld zone have been analyzed for composition using Röntec EDX (Energy Dispersive X Ray Analysis) analyzer attached to LEO Scanning Electron Microscope. Shimadzu XRD- 6000 was used for X-Ray Diffraction analysis of the sintered $\mathrm{Fe}+\mathrm{Al}$ powder specimens using $\mathrm{Cu} \mathrm{K} \alpha$ radiation with a step size of $1^{\circ}$ per minute for $2 \theta$ range of $20-120^{\circ}$. The steel stub was made from unalloyed low $\mathrm{C}$ steel rod, typically containing $0.43 \mathrm{Mn}, 0.083 \mathrm{C},<0.1 \mathrm{~S}+\mathrm{P}$ and $\mathrm{Bal}$. Fe, i.e. falling into category of AISI 1006. The welds were carried out at voltages of 100,120,130, 140, and 150V using Telwin Aluspotter 6100 capacitor discharge stud welding machine with a preinstalled capacitor of $66 \mathrm{~K} \mu \mathrm{F}$. The welding gun pressure was $29.7 \mathrm{kN}$, which was measured with a hydraulic force-meter. A constant gun pressure was used for all welds. A shielding gas was not used because of the extremely short arc duration. The mechanical testing was not carried out due to the size and the shape of specimens. The calculations for the frequency vs. inclusion size graph were based on about 35 inclusions that were selected randomly within three SEM images. The weld depths were measured using Olympus BX series optical microscope attached with a micrometer ruler, taking the average of vertical net distance from the surface of the compacted powder specimens.

\section{Results and Discussion}

The powder compacts were analyzed by XRD technique to reveal as to whether they contained intermetallics phase formed during microwave sintering. Figure 1a presents a typical XRD diffraction pattern and a microstructure from $\mathrm{Fe}-26 \mathrm{Al}$ at.\% sintered powder mixture compact. Both Fe and Al elemental peaks appear separately in XRD results, suggesting that there is no substantial amount of detectable diffusion reaction occurred within the compacts i.e. the formation of intermetallics. However, Figure $1 \mathrm{~b}$ in BSE (Back Scattered Electron) mode clearly shows that there is a reaction zone between $\mathrm{Al}$ and $\mathrm{Fe}$ particles.

\subsection{The effect of arc voltage with low C steel stub}

The joinability of steel stub to microwave sintered $\mathrm{Fe}-\mathrm{Al}$ powder compacts has been investigated by varying the discharge voltage. The initial examination of the weld zone suggests that all the joints are well formed and strong enough for static loading. However, metallographic examinations on the weld zones showed that a discontinuous layer of non metallic compounds existing at the interface between low $\mathrm{C}$ steel stud and the powder compact, mostly in laminar and globular forms (Figures 2-6).

The formation of more non-metallic compound is also seen within the powder compacts in HAZ (Heat Affected Zone), suggesting that the fast cooling due to low heat input during the welding caused further cohesion between the metal powders in compacts (Figures 3a, 3c, 4a-6a). The melting of $\mathrm{Al}$ powders in the compacts during arc discharge accelerate the chemical reaction in this zone and promotes further cohesion between similar and dissimilar powders. In addition, thin cracks lying parallel to the joint direction and discontinuous short thin cracks can also be observed on powder compact side and in the weld zone (Figure 3c). With increasing discharge voltage, the number and the size of the cracks within the weld zone (Figures $4 \mathrm{a}$ and 5a) increased gradually, probably, in response to increase of high volume of intermetallics phase(s) formed in the region, also assisted by a high cooling rate due to relatively small volume of melt. High heat input with fast cooling rate leads to the occurrence of high thermal gradient after the solidification in the weld zone within which many intermetallic phases is bound to form ${ }^{15}$. This, subsequently, gives rise to the formation of cracks due to intermetallics' intrinsically inferior low temperature mechanical properties. In Figure 5a and 6a, few thin cracks are also seen in the steel stud as well as in

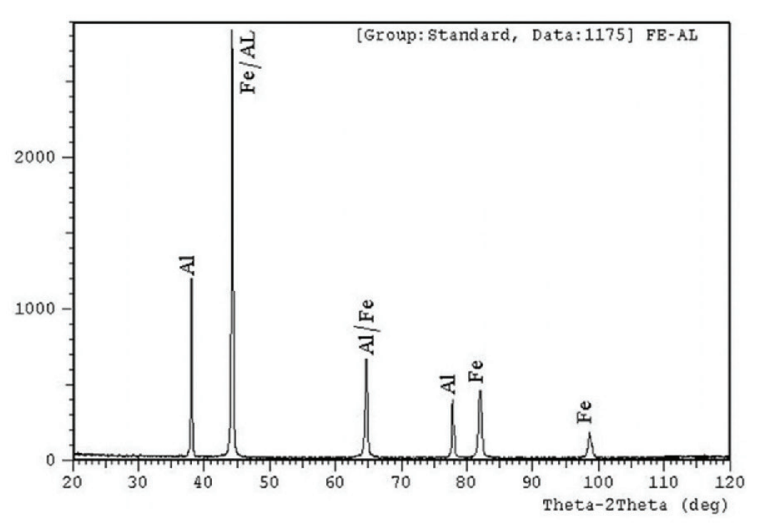

(a)

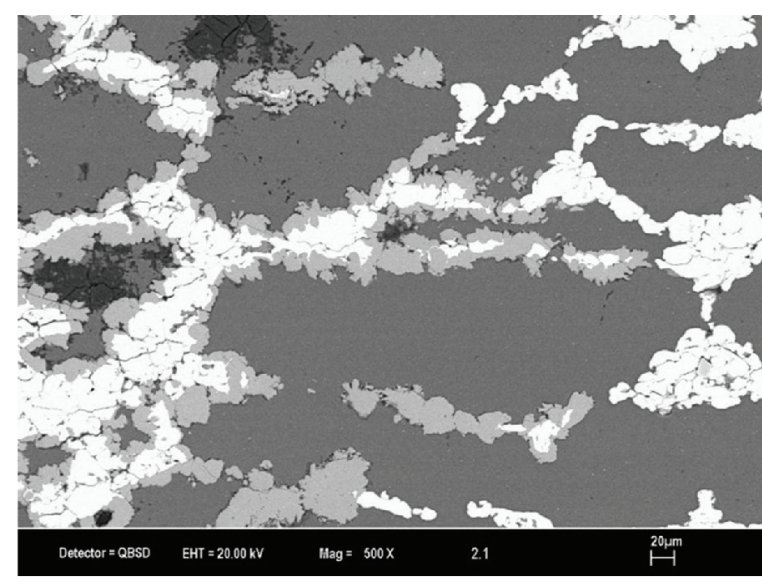

(b)

Figure 1. a) XRD diffraction pattern and b) a typical microstructure from sintered $\mathrm{Fe}-26 \mathrm{Al}$ at. $\%$ powder mixture. 


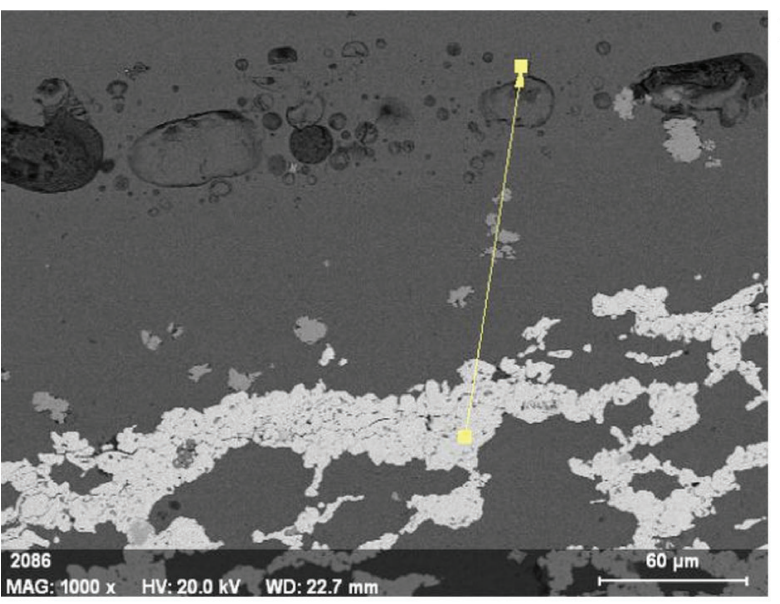

(a)

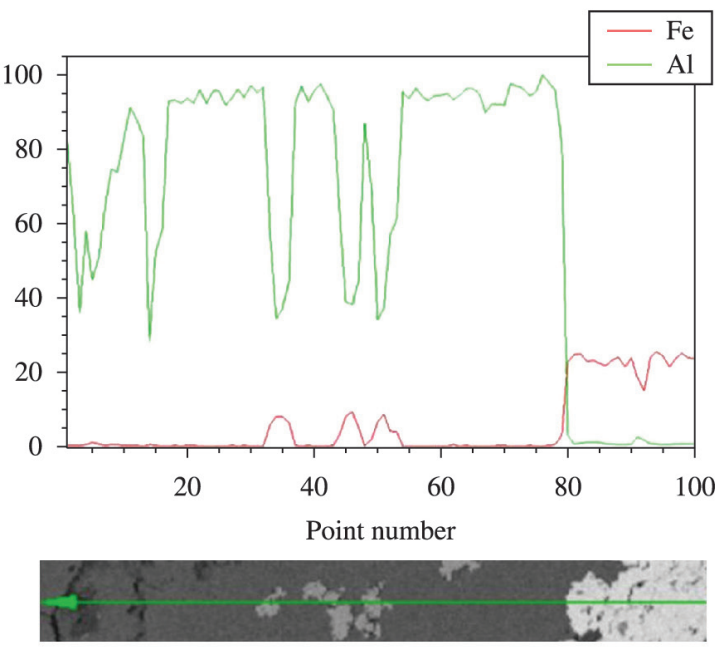

(b)

Figure 2. a) The joint interface of weld zone formed by low $\mathrm{C}$ steel stub welded at 100V, b) The line analysis across the weld zone.

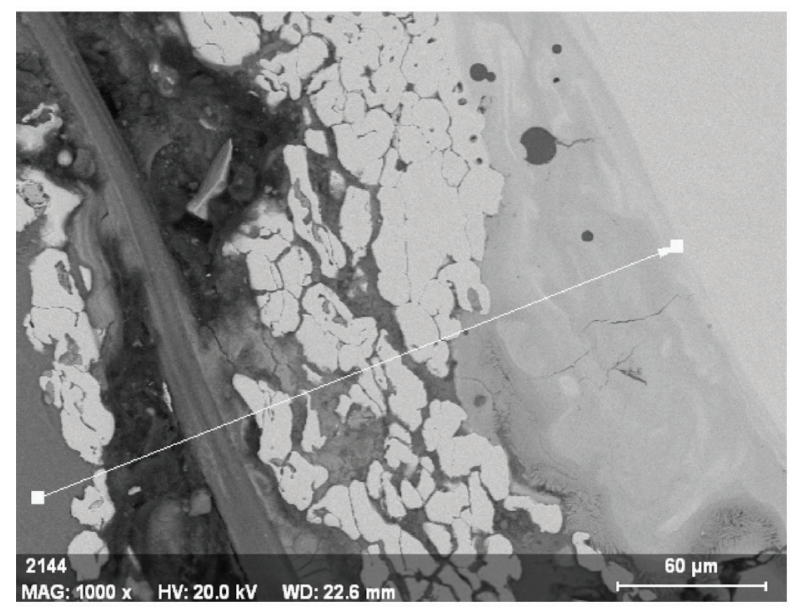

(a)

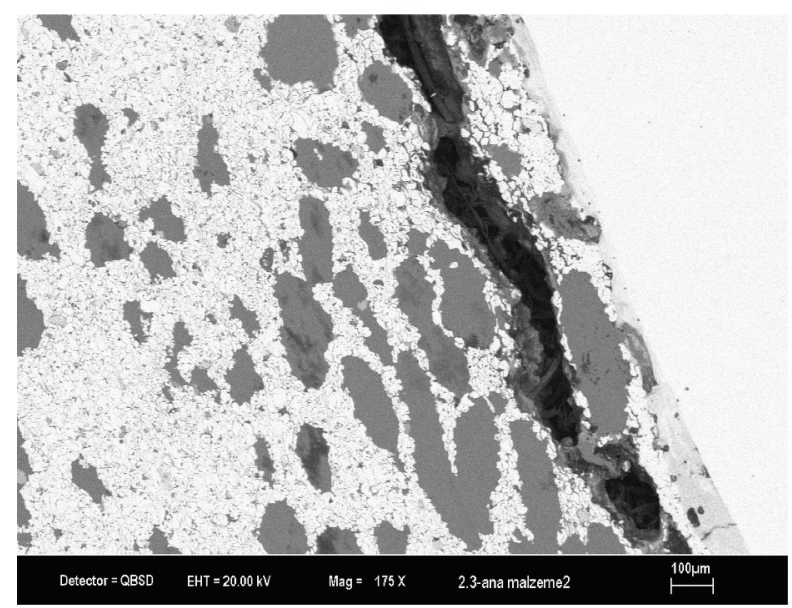

(c)

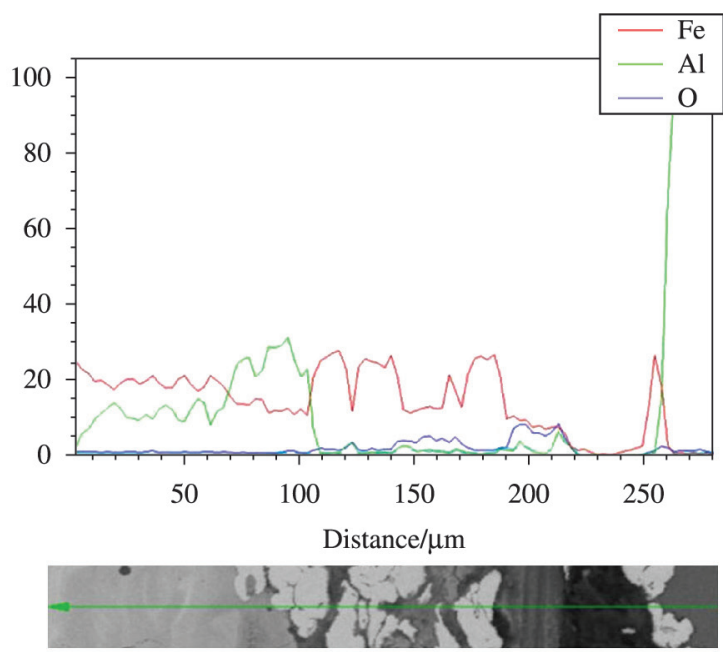

(b)

Figure 3. a) The joint interface of weld zone formed by low alloy steel stub welded at $120 \mathrm{~V}, \mathrm{~b}$ ) the line analysis across the weld zone, c) side cracking adjacent to weld zone. 


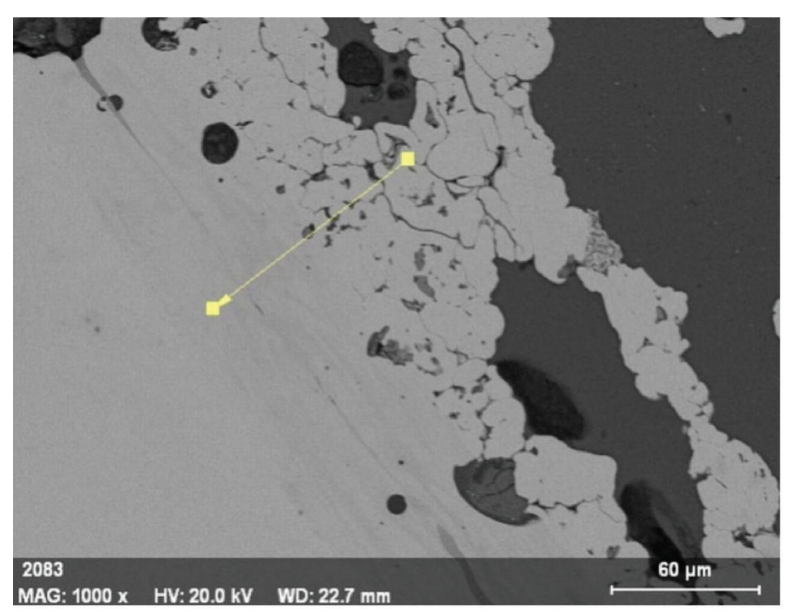

(a)

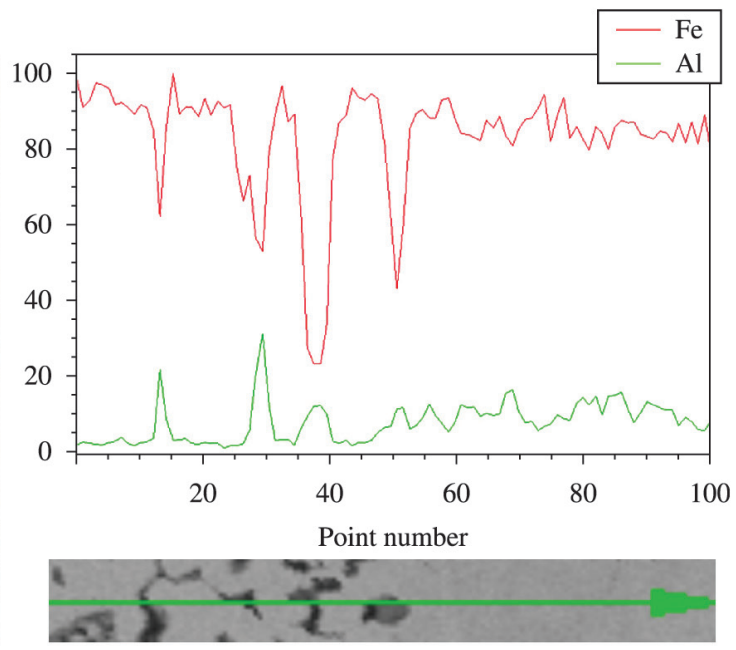

(b)

Figure 4. a) The joint interface of weld zone formed by steel stub welded at $130 \mathrm{~V}$, b) the line analysis across the weld zone.



(a)



(b)

Figure 5. a) The joint interface of weld zone formed by steel stub welded at $140 \mathrm{~V}$, b) the line analysis across the weld zone.

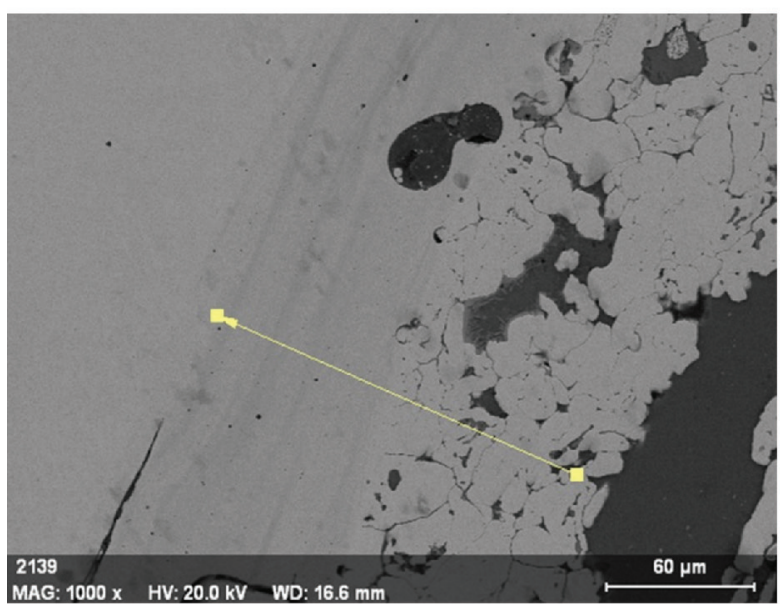

(a)

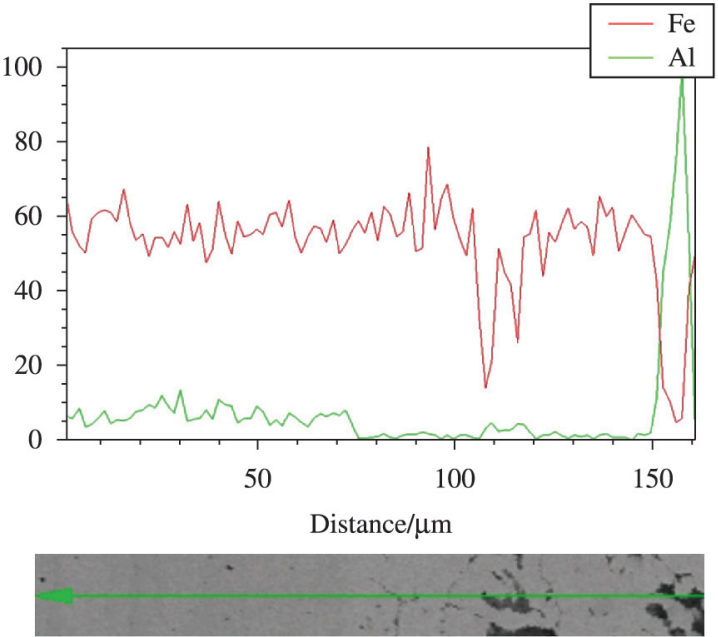

(b)

Figure 6. a) The joint interface of weld zone formed by steel stub welded at $150 \mathrm{~V}$, b) the line analysis across the weld zone. 


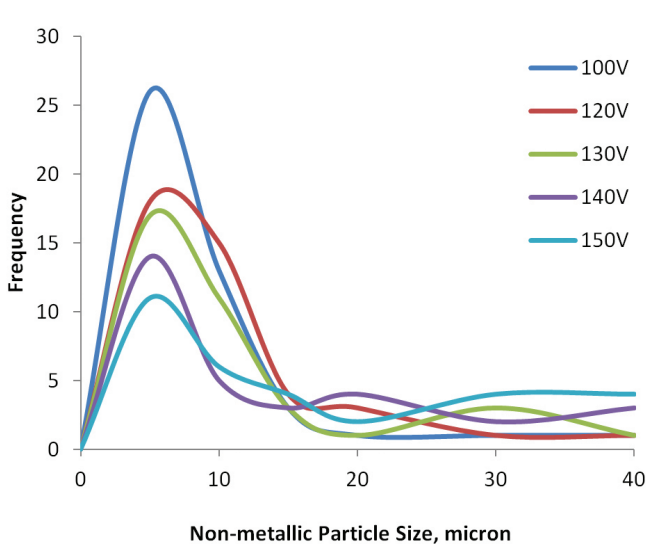

(a)

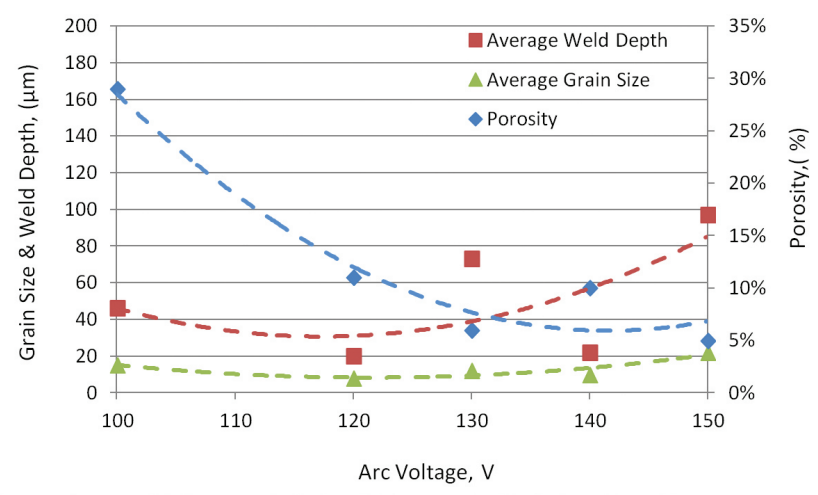

(b)

Figure 7. a) The frequency-size distribution curve for non metallic particles and b) grain size, weld depth and porosity measured in weld zone.

powder compacts. The thickness of oxidation layer also behaves in a similar manner i.e. increases in thickness by the increasing arc voltage. There is no apparent heat affected zone occurred on the steel studs.

In weld zone, the formation of intermetallics are assumed on the basis that $\mathrm{Fe}$ and $\mathrm{Al}$ peaks changes according to ratio of $\mathrm{Al}: 3$ and $\mathrm{Fe}: 1$, giving a stoichiometric compound formula of $\mathrm{Al}_{3} \mathrm{Fe}$ as seen in Figure $2 \mathrm{~b}$. The amount of such intermetallics is small and only limited to weld zone and it may not be detected by the X-Ray diffraction method. The overall composition of weld zones are also interesting to note that the $\mathrm{Al}: \mathrm{Fe}$ ratio in the weld zone changes with increasing arc voltage. It is approximately $1: 3$ for $100 \mathrm{~V}, 3: 5$ for $120 \mathrm{~V}, 1: 9$ for $130 \mathrm{~V}, 1: 10$ for $140 \mathrm{~V}$ and finally $1: 15$ for $150 \mathrm{~V}$ (Figures 3b-6b). It shows a gradual decrease of $\mathrm{Al}$ within the weld zone in which higher heat input is generated at higher arc voltages. The formation of compositionally $\mathrm{Fe}$ rich weld zones may be assisted with possible two different mechanisms. The first mechanism that can be suggested is the selective evaporation of $\mathrm{Al}$ during the firing of arc to form plasma due to its lower evaporation temperature. Nevertheless, according to data given by Block-Bolten and Eager $^{16}$, when welding Fe-10Al alloy, Fe will evaporate before $\mathrm{Al}$ as the vapour pressure of $\mathrm{Al}$ is expected to be higher in 1:9(Al:Fe) alloys than that of $\mathrm{Fe}$ at the temperature range of approximately $2530^{\circ} \mathrm{C}-1590^{\circ} \mathrm{C}$. Secondly, the total heat input increases by the arc voltage applied and consequently favouring the formation of more oxides of $\mathrm{Al}$ in weld zone, making the reaction zone poor of $\mathrm{Al}$ and rich of Fe. The former requires a high heat input weld energy and large quantity of molten weld volume exposed to normal air pressure. However, the volume of the molten metal in stud welding is comparatively small as its heat input. The latter, however, appears to be plausible explanation for $\mathrm{Fe}$ rich zones in the weld region because the weld is carried out in ambient air pressure, which increases the likelihood of Al forming oxides in the weld region. This can be substantiated by the presence of non metallic particles in the weld zone. As seen in Figure 7a, the frequency of non metallic particles decreases with increasing arc voltage but the size of non metallic particles increases in size. As the arc voltage determines the shape of weld joint ${ }^{17,18}$ by making it wider and less penetrant, the volume of melt is appears to be less affected since the thicknesses of weld zone are almost similar.

The weld depth and porosity show inverse relationship as the high heat input is able to melt a substantial amount of mating materials which make the amount of air trapped lower in overall volume. This improves both porosity and average non metallic particle size in general (Figure $7 b$ ). Considering the fact that the frequency of non-metallic particles becomes low in number with increasing arc voltage, total number of inclusions i.e. the number of inclusions multiplied by frequency, does not drastically change. This implies that the volume of chemical reaction does not significantly change since the surface area of interest for the discharge are all the same but the heat input due to increasing arc voltage has an important effect on the volume of melt and physical properties of product phase. As stated above, the heat loss from a smaller volume is fast and hence creating smaller volumes of products along the weld reaction zone, but the elevated heat input can cause excessive heat build up in the weld reaction zone and slow down cooling rate, promoting further growth (increasing the size) of the products i.e. oxides of $\mathrm{Fe}$ and $\mathrm{Al}$.

\section{Conclusions}

The effect of stud welding voltage was investigated using low $\mathrm{C}$ steel stubs on microwave sintered Fe-26Al powder mixture without gas protection. It has been shown that welds with steel stubs are prone to side cracking and excessive oxide formation in the weld zone. On the other hand, following the welding, the compacted metal powder specimen primarily suffers from the oxidation and lack of strength between metal powders adjacent to weld zone. With increasing discharge voltage, the number and the size of the cracks and the size of oxides within the weld zone gradually increased. The type of oxides in the weld zone determines the type of failure following the welding process. 


\section{References}

1. Kurt A, Uygur I and Ates H. Effect of porosity content on the weldability of powder metal parts produced by friction stir welding. Materials Science Forum. 2007; 534-536:789792. http://dx.doi.org/10.4028/www.scientific.net/MSF.534536.789

2. Cakmakkaya $\mathrm{M}$ and Talas S. Joining of microwave sintered Fe-26Al, Fe-30Al, Fe-26Al-14Ti and Fe-30Al-14Ti powder mixtures by diffusion bonding using $\mathrm{Cu}$ interlayer. Journal of the Faculty of Engineering and Architecture of Gazi University. 2012; 27(1):91-98.

3. Kurt A and Ates H. Investigation of weldability of P/M bronze materials by TIG welding technique. Advanced Materials Research. 2007; 23:315-318. http://dx.doi.org/10.4028/www. scientific.net/AMR.23.315

4. Selcuk C, Bond S and Woollin P. Joining processes for powder metallurgy parts: a review. Powder Metallurgy. 2010; 53(1):711. http://dx.doi.org/10.1179/003258910X12680617015249

5. Maki S, Harada Y and Mori K. Sinter-joining of different metal powder compacts using resistance heating. Journal of Materials Processing Technology. 2003; 143:561-566. http:// dx.doi.org/10.1016/S0924-0136(03)00361-3

6. Arik H, Aydin M, Kurt A and Turker M. Weldability of $\mathrm{Al}_{4} \mathrm{C}_{3}$ Al composites via diffusion welding technique. Materials \& Design. 2005; 26(6):555-560. http://dx.doi.org/10.1016/j. matdes.2004.07.017

7. Jayabharath K, Ashfaq M and Venugopal P. Investigations on the continuous drive friction welding of sintered powder metallurgical (P/M) steel and wrought copper parts. Materials Science and Engineering A. 2007; 454:114-123. http://dx.doi. org/10.1016/j.msea.2006.11.026

8. Foroutan I, Mamoory RS and Hosseinabadi N. Aluminacopper joining by the sintered metal powder process. Ceramics International. 2010;36 (2):741-747. http://dx.doi. org/10.1016/j.ceramint.2009.10.016

9. Wahba M, Kawahito Y, Kondoh K and Katayama S. A fundamental study of laser welding of hot extruded powder metallurgy (P/M) AZ31B magnesium alloy. Materials Science and Engineering A. 2011; 529:143-150. http://dx.doi. org/10.1016/j.msea.2011.09.010

10. Hamill J. Weld techniques give powder metal a different dimension. Metal Powder Report. 2007; 62(5):22-31. http:// dx.doi.org/10.1016/S0026-0657(07)70106-6

11. Agrawal D. Microwave sintering, brazing and melting of metallic materials. In: Proceedings of the Sohn International Symposium on the Advanced Processing of Metals and Materials; 2006; San Diego. TMS; 2006. p. 183-192.

12. Aastrup P, Moe A and Knudsen P. Joining methods applied to sintered Al products. Danish Atomic Energy Agency; 1966. Riso Report n. 145.

13. Halldin GW, Patel SN and Duchon GA. Welding of 316L P/M stainless steel. Progressive Powder Metallurgy. 1984; 39:267280 .

14. Avsar E, Durlu N, Atas A, Bozaci C and Ozdural H. Joining of iron based powder metallurgy parts with sintering. Journal of the Faculty of Engineering and Architecture of Gazi University. 2010; 25/4:713-718.

15. Gould, JE and Stotler TV. Application of flash welding to a titanium aluminide alloy-microstructural evaluations. Journal of Engineering for Gas Turbines and PowerTransactions of the ASME. 1993; 115(1):177-183. http://dx.doi. org/10.1115/1.2906674

16. Messler RW. Principles of welding. Weinheim: Wiley-VCH Verlag; 2004

17. Tewari SP, Gupta A and Prakash J. Effect of welding parameters on the weldability of material. International Journal of Engineering Science and Technology. 2010; 2(4):512-516.

18. Murphy AB. The effects of metal vapour in arc welding. Journal of Physics D: Applied Physics. 2010; 43400. 